\title{
DO PRECONCEITO À (IM)POLIDEZ: ASPECTOS SOCIAIS, IDEOLÓGICOS E LINGUÍSTICOS QUE CIRCUNSCREVEM PRÁTICAS RACISTAS E SEXISTAS NO FACEBOOK
}

\author{
(From prejudice to (im)politeness: social, ideological and linguistic aspects that produce racist and \\ sexist practices on facebook)
}

Geórgia Maria Feitosa e Paiva ${ }^{1}$

(UNILAB)

Tatiana Martins Oliveira da Silva ${ }^{2}$

(UNILAB)

\section{RESUMO}

As interações virtuais muitas vezes são uma extensão dos encontros face a face, solidificando-se nos espaços digitais como lócus discursivo de práticas de racismo e o sexismo. Partindo dos estudos da Sociologia, Pragmática e Sociolinguística Interacional, nosso objetivo é compreender, a partir de Fanon (2008), Van Dijk (2017), Brown e Levinson (1987) e Culpeper (1996; 2011), como o preconceito se materializa em (im)polidez linguística através de postagens no Facebook. Realizamos uma pesquisa qualitativa, exploratória e descritiva, pela qual selecionamos uma postagem em um grupo no Facebook sobre um possível caso de assédio entre um estudante estrangeiro e uma estudante brasileira. Para isso, selecionamos e analisamos as respostas mais relevantes, segundo os critérios da própria rede social. Os resultados demonstraram que as estratégias de polidez linguística foram usadas tanto para compor uma imagem positiva do possível agressor, especialmente para pedir apoio aos membros do grupo em relação a ele. Além disso, verificamos uma amálgama de estratégias de polidez e impolidez quando o efeito produzido era o de atacar um dos membros do grupo, a vítima ou o suposto agressor. Nossa investigação apresentou os fundamentos históricos, ideológicos, sociais e contextuais para o evento, além de uma análise das estratégias de polidez e impolidez utilizadas pelos participantes do grupo. Concluímos que os enunciadores buscam alternar entre a polidez e a impolidez linguística para a produção de mensagens preconceituosas.

Palavras-chave: Face. (Im)polidez Linguística. Preconceito Racial. Sexismo.

\begin{abstract}
Virtual interactions are often an extension of face-facing encounters, solidifying in digital spaces as the discursive discourse of racism and sexism practices. Starting from the studies of Sociology, Pragmatics and Interactional Sociolinguistics, our goal is to understand, from Fanon (2008), Van Dijk (2017) Brown and Levinson (1987) and Culpeper (1996; 2011), as the prejudice of materializing in (im) language policy through Facebook posts. We conducted a qualitative, exploratory and descriptive survey whereby we selected a post in a Facebook group about a possible case of harassment between a foreign student and a brazilian student. For this, it selects and analyzes as the most relevant answers, according to the criteria of the social network itself. The results demonstrated how politeness strategies were used both to create a positive image of the potential offender and to solicit support from group members in relation to him; In addition, there is condensation between politeness and impoliteness strategies when the effect was to attack

1 Doutora e mestre em Linguística (2013) pela Universidade Federal do Ceará. Professora Adjunto A da Universidade da Integração Internacional da Lusofonia Afro-Brasileira (UNILAB), editora-chefe da Revista de Estudos Linguísticos Mandinga. Líder do Grupo de Pesquisa Preconceito, Polidez e Impolidez Linguística (GEPPIL), tendo interesse nas áreas de polidez, impolidez, preconceito, discurso intolerante, comunicação e mídias digitais. E-mail: georgiafeitosa@unilab.edu.br

2 Mestranda em Estudos da Linguagem pela Universidade da Integração Internacional da Lusofonia Afro-Brasileira (UNILAB). Cursando Licenciatura plena em História. Bolsista do Programa Residência Pedagógica (CAPES) subprojeto de História e Membro do Grupo de Pesquisa Preconceito, Polidez e Impolidez Linguística (GEPILL/UNILAB). E-mail: tatiladypcd@gmail.com
\end{abstract}


one of the group members, the victim or the supposed aggressor himself. Our investigation shows the historical, ideological, social and contextual foundations for the event, as well as an analysis of the politeness and impoliteness strategies applied by the group participants. Conclude that the statements seek alternate between politeness and linguistic impoliteness for the production of biased messages.

KeyWords: Face. (Im)politeness. Racial Prejudice. Sexism.

\section{RESUMEN}

Las interacciones virtuales son a menudo una extensión de los encuentros cara a cara, solidificándose en espacios digitales como un lugar discursivo de prácticas de racismo y sexismo. A partir de los estudios de Sociología, Pragmática y Sociolingüística Interaccional, nuestro objetivo es comprender, a partir de Fanon (2008), Van Dijk (2017) Brown y Levinson (1987) y Culpeper (1996; 2011), cómo el prejuicio se materializa en(des)cortesía lingüística a través de publicaciones en Facebook. Realizamos una investigación cualitativa, exploratoria y descriptiva mediante la cual seleccionamos una publicación en un grupo de Facebook sobre un posible caso de acoso entre un estudiante extranjero y una estudiante brasileña. Para ello, seleccionamos y analizamos las respuestas más relevantes de acuerdo con los criterios de esa red social. Los resultados mostraron que las estrategias de cortesía lingüística se utilizaron tanto para componer una imagen positiva del posible agresor, como para solicitar apoyo de los miembros del grupo en relación a él. Además, encontramos una amalgama de estrategias de cortesía e descortesía cuando el efecto era atacar a uno de los miembros del grupo, la víctima o el presunto acosador. Nuestro trabajo presentó los fundamentos históricos, ideológicos, sociales y contextuales para el evento, así como un análisis de las estrategias de cortesía y descortesía utilizadas por los participantes del grupo. Concluimos que los enunciadores buscan alternar entre la cortesía y la descortesía lingüística para la producción de mensajes prejuiciosos.

Palabras clave: Fachada. (Des)cortesía lingüística. Prejuicio racial. Sexismo.

Recebido em: dezembro 2019

Aceito em: dezembro 2019

DOI: $10.26512 /$ les.v20i3.28632

\section{INTRODUÇÃO}

Poucos discordariam que atualmente não existe racismo ou sexismo no Brasil. Como integrantes dos três pilares formadores da sociedade brasileira desde sua colonização, o racismo e o Sexismo são um fenômeno de caráter ideológico (HIRATA, 2014). Neles temos a produção de marcadores de identidade nos grupos sociais e de simbologias (MUNANGA, 1999; HIRATA, 2014). Dentre as simbologias podemos listar desde a identificação com determinada categoria racial/étnica e de gênero como branco e/ou negro, homem/mulher até os estilos de roupa que pertencem a cada raça e a cada gênero (moda africana, moda parisiense, moda feminina, moda masculina etc.). A divisão dessas simbologias e desses grupos sociais não deixam de perpassar suas práticas textuais-discursivas. Primeiro por que "quando dominamos uma língua, dominamos também o mundo que ela expressa" (FANON, 2008, p. 34). Assim, quando dominamos a língua oficial portuguesa também nos foi herdada toda a herança cultural dela advinda. Segundo, porque adotamos um conceito de enunciação como produto das relações sociais e dos discursos nela 
recorrentes. Assim, os marcadores de identidade social que são expressos por meio dos discursos que produzimos são perpassados pelas divisões de raça e de gênero.

Levando-se em consideração essa divisão, esses valores raciais e de gênero são usados para categorizar e excluir as pessoas através da condenação de algum hábito ou de alguma cultura que se entenda própria de determinado gênero/raça. Lembramos que os discursos intolerantes e os estereótipos por eles produzidos se baseiam na dicotomia branco/negro e homem/mulher, e pendem para o lado mais estereotipado da dicotomia (no caso, os negros e as mulheres), causando um duplo preconceito quando o indivíduo se categoriza nessas duas faixas. Isso é o que denominamos Interseccionalidade.

Correntes teóricas, como as produzidas por Ângela Davis e Helena Hirata, trabalham bem com a Interseccionalidade entre raça/gênero. Tanto Ângela Davis como Helena Hirata ${ }^{3}$ efendem que a raça e o gênero são categorias que se completam e que os fenômenos sociais, a partir das opressões que geram, só podem ser entendidos a partir dessas duas categorias. Elas também defendem que identidade negra e identidade feminina são demarcadores sociais que solidificam o indivisível e o permanente das características e das posições sociais que os indivíduos representam e os colocam automaticamente como "vítimas" de seus estigmas, ao passo que os criminalizam por suas posições e/ou representações.

Diante disso, este trabalho busca compreender, a partir de Fanon (2008), Van Dijk (2017), Brown e Levinson (1987) e Culpeper (1996; 2011), como o preconceito se materializa em (im)polidez linguística através de postagens no Facebook. Acreditamos que as práticas polidas e impolidas materializam o discurso intolerante motivado por preconceitos, sejam eles em relação ao sexo, à religião, à raça, entre outros. Para isso, realizamos uma pesquisa exploratória e descritiva, pela qual selecionamos exemplares de comentários de uma postagem sobre um relato de assédio sexual no intercampi da Universidade publicada em um grupo na rede social Facebook.

Como justificativa para a proposta deste artigo, valemo-nos justamente da quebra desse paradigma e da evidência do sujeito fruto das violências raciais e de gênero colocado a partir de suas próprias representações sociais como vítima dos preconceitos produzidos sobre suas representações sociais. Assim, almejamos, como objetivo geral deste artigo, compreender como o preconceito se materializa em (im)polidez linguística através de postagens no Facebook. A compreensão de como esse preconceito se materializa perpassa um debate que não é novo no Brasil, como é o caso dos estudos de Fanon (2008) e de Van Dijk (2017), a respeito de Raça e de Gênero.

\footnotetext{
${ }^{3}$ Vide Davis (2011) e Hirata (2014).
} 
Este artigo está dividido em dois tópicos teóricos, sendo o primeiro dedicado a discutir as relações entre racismo e gênero a partir de uma perspectiva pós-estruturalista; o segundo ao debate acerca da relação entre discurso intolerante e (im)polidez. Logo após tais seções, apresentamos nosso caminho metodológico, para somente então expormos a análise das postagens.

\section{RACISMO E GÊNERO SOB UMA PERSPECTIVA CONCEITUAL PÓS-ESTRUTURALISTA}

O pós-estruturalismo, definido como a superação do paradigma estruturalista, adveio com a virada linguístico-pragmática, trazendo uma perspectiva de linguagem para além de seu sistema interno, considerando sua diversidade, sua pluralidade e sua ambiguidade, e levando-se em conta a atribuição de significado, sobretudo, no âmbito extra-linguístico. Dessa forma, consideramos raça e gênero como fatores extra-linguísticos que interferem no significado das sentenças, por serem estigmas que perpassam os valores culturais de nossa sociedade e formam a diversidade de estratégias linguísticas a partir das quais os falantes podem ser considerados polidos ou impolidos. Assim, definimos racismo, segundo Guimarães (2005, p. 11), como

uma forma bastante específica de "naturalizar" a vida social, isto é, de explicar diferenças pessoais e culturais a partir de diferenças tomadas como naturais. Encontra-se de modo implícito na ideia de racismo de uma natureza geral que determina aspectos individuais ou socioculturais.

Guimarães (2005) menciona que o racismo é uma forma de naturalizar as diferenças sociais e culturais, colocando-as como inferiores. Como uma das formas de naturalizar o mundo social, o gênero também estaria nessa definição, já que este naturaliza e legitima diferenças culturais e sociais, por exemplo, na destinação de tarefas a homens e a mulheres, e no valor dado atais tarefas. Da mesma forma, o racismo também define naturalizações para os papéis sociais que brancos e negros atuam. Um exemplo claro disso seria as profissões que envolvem trabalho manual, como empregada doméstica, representadas por categorias de mulheres negras, e a profissão de médico representada por homens brancos.

Tanto os que carregam o estigma do gênero quanto os que carregam o estigma da raça passam por um processo de estigmatização desde o seu nascimento. Esse processo envolve especificamente os símbolos que carregam no corpo. No caso racial, a cor de pele, já no caso do gênero, o sexo feminino (BACILA, 2015). Esse estigma perpassa por sua negação. Van Dijk em seu Livro "Discurso e Poder" dedica um capítulo específico para discutir a negação do racismo denominado "O discurso e a negação do racismo". Ele analisa a negação do racismo em discursos do cotidiano, da mídia (jornais) e oficiais, apontando a negação do racismo como uma estratégia de 
impolidez linguística. $\mathrm{O}$ gênero também se encaixaria nessa categoria, já que a mulher é o oposto negativo dos homens, sendo a negação de sua representabilidade uma forma de inferiorização.

Tanto no gênero como na raça há um processo de deslegitimação, associando a vítima à responsabilidade pela sua "suposta existência". Assim, alegações similares a "o racismo foi criado pelos negros" e "ela foi assediada por que estava de minissaia", comuns em comentários de redes sociais, integrariam

uma dupla estratégia: por um lado, uma estratégia de autoapresentação positiva e, por outro, formas sutis, indiretas e às vezes bastante explícitas de autoapresentação negativa (...) acompanhada de preservação social das faces. (VAN DIJK, 2017, p. 157).

Através da polidez, os enunciados conseguem minimizar os efeitos potencializadores de suas falas ofensivas, ao passo que, ao negar sua existência, deslegitimam discursos que protestam contra o racismo e contra o sexismo. Com a polidez há também a preservação das faces dos interlocutores e dos membros que pertencem ao mesmo discurso por eles empregados. A negação do racismo e do sexismo é apenas uma das estratégias de polidez que tentaremos demonstrar neste artigo em publicações do Facebook. Entretanto, existem muitas outras, como a apelação para o caráter moral do indivíduo, a destruição de sua imagem e/ou a associação naturalizada de seus comportamentos com os de sua "espécie/origem" dentre outros. As estratégias que perpassam as naturalizações performáticas do discurso serão demonstradas através dos mecanismos da (im)polidez linguística na constituição do discurso intolerante.

\section{O DISCURSO INTOLERANTE E A REALIZAÇÃo DA (IM)POLIDEZ LINGUÍSTICA}

Conforme Leite (2017), o discurso intolerante ou a intolerância é a materialização de um discurso preconceituoso que pode se manifestar em diversos gêneros discursivos. A autora, ao analisar a intolerância em discursos midiáticos, verificou a existência de uma espécie de padronização linguística que organiza esse discurso, com a finalidade de gerar aceitação por parte da audiência e, ao mesmo tempo, banalizar o Outro e ressaltar o Eu.

A relação entre o "eu" e o "outro", como apontam Allport (1979) e Bacila (2015), parece abrigar uma disputa pela sobrevivência. Os autores narram que, ao longo da história da humanidade, foram (e continuam sendo) propagadas crenças que fundamentam o preconceito, com a finalidade de manter a organização social. Desse modo, os grupos sociais organizam-se para adquirir e manter uma quantidade de bens simbólicos e materiais que devem representar o seu poder dentro de uma sociedade. Quando não os têm e precisam adquirir, ou mesmo quando se sentem 
ameaçados e precisam se proteger, eles propagam a intolerância como instrumento de controle social. Vale ressaltar que a intolerância pode ultrapassar as barreiras linguísticas, chegando a práticas criminosas, como o homicídio.

Assistimos assim a uma "cena", cujos heróis somos sempre o nós e os anti-heróis os outros, e pressupomos que os sujeitos investem fortemente na linguagem para não somente propagar a intolerância, mas, principalmente, para convencer que ela é uma alternativa. Ciente de que esse processo pode ocorrer de modo mais ou menos organizado, Barros (2011) propõe que o discurso intolerante é um discurso de sanção, que tematiza uma relação antagônica entre o Eu e o Outro, podendo operar, de modo racionalizado, como estratégia de convencimento da ideia intolerante.

Neste artigo, propomos que as estratégias e a própria (im)polidez linguística podem atuar como mecanismos de materialização linguística do discurso intolerante, pois acreditamos que a intolerância deve operar de modo mais ou menos padronizado em diferentes situações enunciativas. Antes de adentrar aos conceitos de polidez e impolidez, é preciso conhecer a noção de face proposta por Goffman (1967). O sociólogo publicou na década de sessenta um estudo sobre as interações face a face. Na obra, o autor comenta que a face é uma imagem construída no ato da interação entre o falante e seu interlocutor baseada nos "atributos sociais aprovados" e demonstrados nessa interação.

Assim, o indivíduo tentaria preservar sua face nas interações sociais na medida em que a sua face fosse os seus atributos socialmente aprovados e que desejasse sua atenuação numa interação ou mesmo a credibilidade de que os indivíduos mantêm sua face na forma que os outros a querem. Pensando no conceito de face, teríamos uma face coletiva, ao pensarmos na identidade branca/negra, e ainda teríamos uma face individual, pensando no indivíduo que se reconhece nessas duas categorias. Da mesma forma ocorreria com uma identidade de gênero.

Utilizamos, também, o conceito de estigma de Goffman (1963) no qual encaixamos a categoria raça/gênero como um estigma. A raça, assim como o gênero, se tornaria um marcador de identidade social baseado em qual categoria racial (ou grupo de gênero) as pessoas utilizam numa interação social em redes sociais, definindo suas escolhas pessoais com bases nas representações de sua raça (e de seu gênero).

Segundo Goffman (1963, p. 12), estigma é um atributo depreciativo no qual "deixamos de considerar o indivíduo uma criatura comum e total, reduzindo-o a uma pessoa estragada e diminuída - num caso extremo, uma pessoa completamente má, perigosa ou fraca”. Para o teórico, o estigma é um mecanismo excludente do grupo considerado normal, ao mesmo tempo que se torna uma identidade social do indivíduo estigmatizado. Assim, haveria mecanismos que o indivíduo 
acionaria para preservar e/ou manter sua face, mesmo que estivesse em interação com o estigmatizado ou que ele próprio estivesse sob tal estigma (raça/gênero).

Baseando-nos no conceito de face e de estigma de Goffman (1967), podemos compreender melhor sobre polidez e impolidez linguística. Os estudos de polidez linguística ganharam mais holofotes com a obra de Brown e Levinson (1987). Baseados na noção de face de Goffman (1967) e inspirados pelos trabalhos desenvolvidos por Austin ${ }^{4}$ (1990), Searle (1969;1979), Lakoff (1973), Leech (1983), entre outros, os linguistas Brown e Levinson (1978; 1987) desenvolveram uma teoria a respeito do modo e das razões que suscitam os sujeitos a agirem com polidez em suas atividades de linguagem. Os estudiosos partiram do pressuposto de que a polidez e suas formas de manifestação são universais e devem surgir a partir da interação entre, no mínimo, dois sujeitos racionais, que possuem propósitos comunicativos definidos e alinhados segundo algumas variáveis, a saber: a) o peso do ato de fala, conhecido por (FTA); b) o poder, que diz respeito ao potencial assimétrico das situações assumido pelos interlocutores e; c) a distância, concebida como o nível de intimidade entre eles.

Esses autores desenvolveram um conceito de polidez negativa e de polidez positiva, que se baseia, respectivamente, nas noções de autonomia/território e de afiliação/aprovação. A polidez positiva se baseia nos valores que o falante quer compartilhar e construir numa interação específica; já a polidez negativa, na preservação do território do outro e de si mesmo (PAIVA; MOREIRA; SANTOS, 2016).

$\mathrm{Na}$ polidez positiva estariam os valores que, quando são convenientes revelar (ou seja, quando está em jogo a perda de vantagens ou privilégios), corroboram com uma apresentação valorativa de si, com base em privilégios raciais ou de gênero. Já na polidez negativa, em que está envolvida a ocultação de valores em que o indivíduo não quer revelar, principalmente para preservar sua própria face, estariam envolvidos, por exemplo, a autodeclaração de ser uma pessoa racista ou sexista e ocultação, por parte do indivíduo, em pertencer a determinada raça (branco/preto) ou a determinados rótulos, como o de machista. Isso porque, numa interação específica, o sujeito pode comprometer a sua própria face e a face que os outros esperam dele, ao determinar seu pertencimento racial ou de gênero, o que implica, por conseguinte, se comprometer a uma linha de comportamento e de atos verbais que se esperam de brancos e de pretos.

Essa relação entre a face do indivíduo, o seu estigma (raça/sexo) e as estratégias de polidez envolvidas não deixariam de perpassar os modos julgamentos nas redes sociais dos indivíduos. Suas perspectivas e seus anseios através de suas postagens perpassam as identidades de gênero e de raça,

\footnotetext{
${ }^{4}$ A referência trata de uma versão traduzida para o português do Brasil.
} 
as quais levantam uma bandeira de pertencimento a determinados grupos. É através do pertencimento a essas identidades que os indivíduos escolhem seus posicionamentos políticos e étnicos bem como reforçam ou mitigam estereótipos presentes em grupos em redes sociais.

Tal modelo teórico possibilitou, concomitantemente, o surgimento de diversos trabalhos que se prestaram a verificar a legitimidade universal em situações de fala específicas, e outros que, ao tentarem aplicar a teoria, se depararam com alguns entraves importantes para se compreender a polidez, tal como os linguistas haviam apontado. Tais trabalhos derivaram críticas, especialmente com relação aos aspectos teóricos, culturais, contextuais e intergrupais (WATTS, 2003; KERBRAT-ORECCHIONI, 2006; LEECH, 2014)

Além das críticas ao modelo formalista de Brown e Levinson (1987), também assistimos ao surgimento de outra corrente teórica que parecia se legitimar como antagonista: a impolidez linguística. Em 1996, Culpeper publicou um artigo no periódico Jornal da Pragmática intitulado: Para além de uma anatomia da impolidez. Neste artigo, o linguista iniciava uma longa jornada acadêmica com a finalidade de propor a impolidez linguística também como fenômeno universal. Na sua primeira versão, a teoria da impolidez assumiu as noções de face positiva e negativa, de Goffman (1967), empregadas por Brown e Levinson (1987), caracterizando uma série de estratégias de impolidez direcionadas para essas faces. Como podemos observar, muitas parecem se contrapor àquelas propostas por Brown e Levinson (1987):

Estratégias de impolidez positiva

a) Ignore, censure o outro - deixe de reconhecer a presença do outro.

b) Exclua o outro de uma atividade.

c) Desassociar o outro - por exemplo, negue associação ou comum acordo com o outro.

d) Seja desinteressado, despreocupado e antipático.

e) Use marcadores de identidade inapropriados - por exemplo, use nome e sobrenome quando possui um relacionamento próximo, ou o apelido quando pertence a um relacionamento distante.

f) Use linguagem secreta e obscura - por exemplo, engane o outro com gíria, ou use um código conhecido por outros grupos, mas não o alvo.

g) Busque discordar - selecione um tópico delicado.

h) Faça o outro sentir desconfortável - por exemplo, não evite o silêncio, piada, ou use conversa fiada.

i) Use palavras que são tabus - blasfeme ou use linguagem profana ou abusiva. Chame de outros nomes - use nominações depreciativas.

Estratégias de impolidez negativa

a) Assuste- incutauma crença de que uma ação prejudicial para o outro ocorrerá.

b) Condescenda, desprezeou ridicularize- enfatizeo seu poder relativo, seja desprezível.

c) Não trate o outro seriamente. Menospreze o outro.

d) Invada o espaço do outro- literalmente ou metaforicamente (por exemplo: pergunte por, ou fale sobre algo que é muito íntimo em um dado relacionamento). 
e) Associeexplicitamente o outro aum aspecto negativo - personalize, use os pronomes "eu" e "você".

f) Coloque o endividamento do outro em questão.

(CULPEPER, 1996, apud, MARTINS, 2013, p.67).

Em estudo mais recente (2011), Culpeper realiza uma extensa revisão de sua teoria, e agora, mais embasado por autores que vem estudando não somente a impolidez, mas questões de identidade, gênero, contexto, emoção e intencionalidade, o linguista conceitua impolidez como

uma atitude negativa que diz respeito a comportamentos específicos em contextos particulares. Ela se sustenta nas expectativas, desejos ou crenças sobre a organização social, incluindo, em particular, a identidade de uma pessoa ou um grupo, que é mediado/a por outros em uma interação (CULPEPER, 2011, p. 23).

Diante de tal conceito, observamos que categorizar um ato como impolido ou até mesmo polido não depende exclusivamente das variáveis ou das faces, dependem, sobretudo, de uma série de fatores que, muitas vezes, podem estar encobertos pelas realizações linguísticas, residindo na forma como sujeitos concebem o evento. Essa concepção pode assumir um caráter particular específico dos sujeitos e da situação, como é o caso das interações em redes sociais na internet.

\section{Caminhos metodológicos}

A natureza deste estudo consiste em uma pesquisa descritiva e exploratória, de caráter qualitativo. Ou seja, buscamos descrever e explorar o objeto de pesquisa, considerando seus aspectos subjetivos e descrevendo as estratégias de polidez e impolidez linguística utilizadas nos enunciados de postagens e seu possível potencial efeito de gerar intolerância quanto à diversidade racial e sexual. Escolhemos a pesquisa qualitativa por ser um uma pesquisa que visa a dar profundidade à análise do objeto, que, por sua vez, necessita de um detalhamento descritivo mais aprofundado. Dada a revolução comunicacional das redes sociais, escolhemos analisar postagens de publicações em grupo justamente por representarem a contemporaneidade da linguagem e os valores sociais que surgem do uso dos inteligentes coletivos concentrados em grupos nos sites de redes sociais.

Assim, selecionamos uma postagem publicada no dia 23 de agosto de 2018 e seus comentários em uma comunidade virtual de uma Universidade sediada no Estado do Ceará (Brasil). A postagem trata de um suposto caso de assédio que teria ocorrido entre uma aluna brasileira e um aluno estrangeiro oriundo de um país africano. O caso teria ocorrido dentro dos ônibus Inter-campi

\footnotetext{
${ }^{5}$ Martins (2013) traduziu para a língua portuguesa as estratégias.
} 
da universidade. Vale ressaltar que a postagem selecionada não evidencia uma denúncia isolada, e que o tema já fora tratado outras vezes no mesmo ambiente de interação. O método utilizado para analisar as postagens é a ADC (Análise do Discurso Crítica. Essa perspectiva de análise busca mostrar o discurso e a mudança social nele decorridos a partir do caráter valorativo de uma sentença. Escolhemos esse método por acreditar que as estratégias linguísticas que trazem o discurso intolerante estão intrinsecamente ligadas à mudança social nos discursos produzidos em redes sociais.

Os comentários analisados com o método da ADC serão apresentados através de prints e, por motivos éticos, seus nomes e suas fotos de perfil foram borradas. A análise tanto da postagem quanto dos comentários se dará em duas instâncias: (a) a primeira abordará o caso sob um viés ideológico e contextual; e (b) a segunda demonstrará, por meio da elucidação das estratégias de polidez e impolidez empregadas pelos interlocutores, a realização ou não do discurso intolerante.

\section{Resultados e AnÁlise}

\subsection{Aspectos contextuais e ideológicos da postagem}

A Universidade está para o sujeito como um lugar que ultrapassa as barreiras do conhecimento teórico e acadêmico. Ela assume uma importância transformadora na vida dos sujeitos que buscam, a todo custo, definir e redefinir suas identidades e suas trajetórias de vida. A Universidade, lócus de nossa investigação, surge no contexto da CPLP (Comunidade dos Países de Língua Portuguesa) como a única Universidade internacional, interiorizada e voltada para negros no Brasil. Nela, há uma vasta gama de projetos que visam a minimizar os impactos do racismo através dos estudos sobre a negritude e sua historicidade.

O racismo como sistema institucional e epistemológico inferioriza e torna naturalizada a relação de inferioridade entre negros e brancos. Para Fanon (2008, p. 14), o racismo e o colonialismo deveriam ser entendidos como modos socialmente gerados de ver o mundo e de viver nele. Os falantes do Português Brasileiro são socialmente colonizados para enxergar e categorizar o mundo racialmente. Os estereótipos de negritude advindos da colonização europeia no Brasil têm uma ampla base e aceitação tanto no meio social quanto no linguístico.

Essa linguagem opressiva aos negros é o meio pelo qual as pessoas se comunicam e se expressam. O caráter ideológico do racismo consiste em fazer as pessoas construírem representações da negritude com base na branquitude europeia. Essa construção ideológica do racismo se manifesta diretamente na linguagem, já que esta é o meio pelo qual as pessoas constroem os significados cognitivamente (LAKOFF; JOHNSON, 1980). Desse modo, os sujeitos 
racistas, embora tenham acesso a outras formas de conhecimento, apresentarão entraves importantes para a apreensão de novas formas de conceber o mundo à sua volta.

Nos últimos anos, observamos que o estudo sobre as mulheres tem crescido em várias áreas, principalmente por causa dos movimentos feministas. Contudo ainda são escassos os estudos relacionados nessa área. Dito isto, podemos sugerir que o contexto da Universidade, que se pretende integradora, abriga conflitos importantes sobre raça e gênero, e exala fortemente atitudes e discursos intolerantes, especialmente nos bastidores das redes sociais, como é o caso do grupo no Facebook que coletamos os exemplos apresentados no tópico 4.2.

\subsection{Aspectos linguísticos da postagem}

A postagem foi realizada no dia 23 de agosto de 2018, e, ao que tudo indica, após o incidente ocorrido em ônibus que faz o transporte dos estudantes entre os campi da Universidade. A postagem foi feita por um estudante que não praticou e não sofreu com a prática descrita na postagem. Até a data de coleta das imagens, a mensagem do estudante continha mais de 300 comentários, 156 reações e, após uma pesquisa, se tornou um dos comentários mais relevantes e mais curtidos ou respondidos, levando-se em conta o algorítimo que privilegia as postagens que geraram mais reações. Selecionamos, a partir dessa pesquisa prévia, aqueles que representavam a opinião geral dos que comentaram a postagem, principalmente levando-se em conta a incapacidade de analisarmos todos os comentários, já que estes totalizavam mais de trezentos.

Figura1 - Postagem

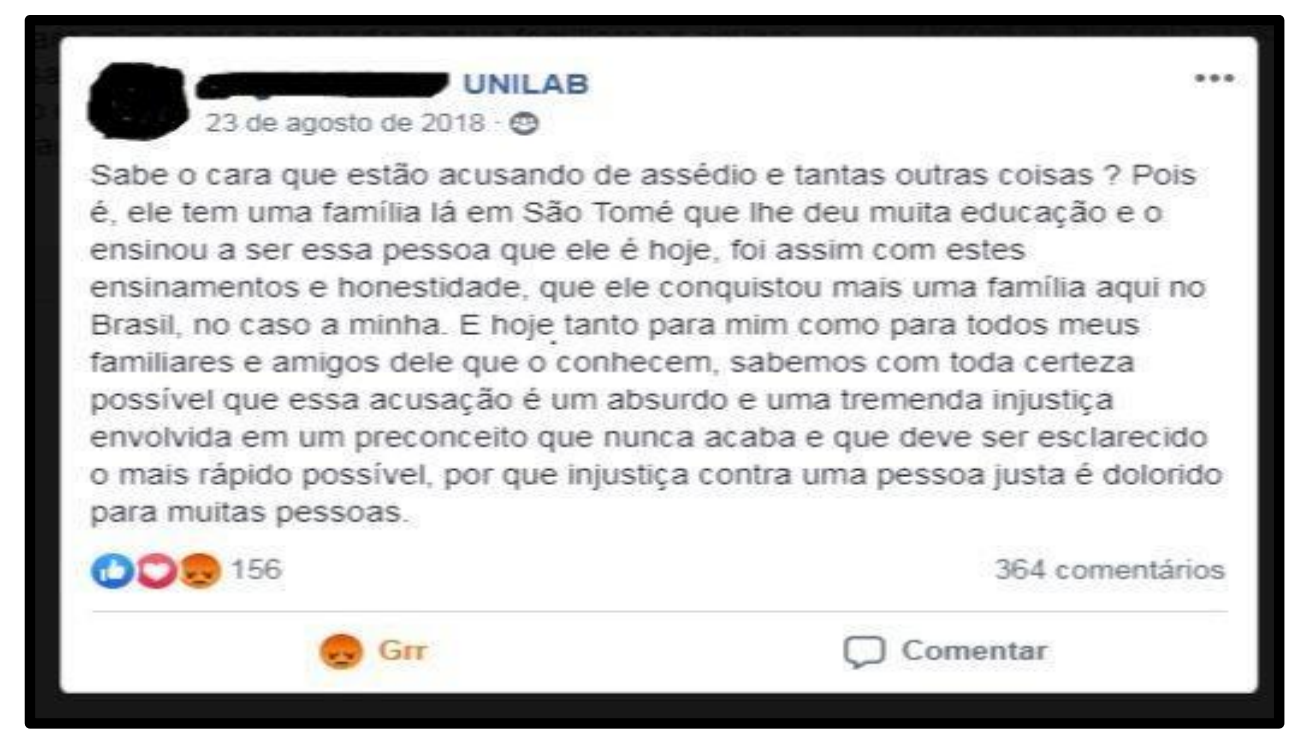

Fonte: https://www.facebook.com/groups/213622388659450/search/?query=ass\%C3\%A9dio\&epa=SEARCH_BOX 
Na figura 1, vemos uma mensagem com mais ou menos 10 linhas, cuja organização temática se distribui em: (a) resgatar a situação vivenciada no ônibus; (b) apresentar o suposto agressor; (c) fornecer razões para a construção de sua boa reputação; e (d) denunciar o preconceito contra os estudantes estrangeiros. O emissor da mensagem distribui os temas de forma mais ou menos igual, sendo que a ênfase maior está para os aspectos c e d.

Notemos que, no enunciado produzido na postagem (figura 1), vemos uma linha de defesa do rapaz que está sendo acusado, alegando sua boa formação educacional, sua moral e sua honestidade e argumentando que a acusação que fazem contra ele é uma injustiça e é decorrente de preconceito (racial), por ele ser um jovem negro e estrangeiro. Na primeira investida, assistimos a um trabalho de face, em prol da construção da imagem positiva do Outro, o que nos termos de Goffman (1967) sinaliza os "atributos socialmente aprovados". A seguir veremos os comentários dessa postagem. Vale ressaltar que esse Outro é estrangeiro e, apesar de compartilhar os mesmos espaços e gozar dos mesmos direitos dos estudantes brasileiros, carrega em si outro traço estigmatizado (a sua raça), o que, para Bacila (2015), configura-se como uma amálgama de estigmas.

$\mathrm{Na}$ mensagem apresentada na figura 1, podemos observar que o seu autor busca desconstruir o aspecto subjetivo atribuído ao estigma do estrangeiro/negro, quando realiza uma série de estratégias de polidez linguística, a saber: (a) aceite, aumente, delimite o terreno comum; (b) forneça ou peça razões; e (c) forneça presentes ao ouvinte. Nesse caso, na categoria de ouvinte também está incluído o estudante acusado de assédio, uma vez que sua postagem foi publicada em modo público em um grupo fechado com mais de três mil membros na rede social.

Figura 2 - Comentários "Machismo"

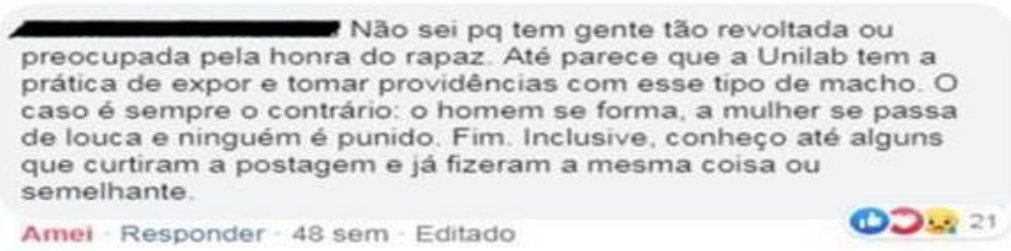

Fonte: https://www.facebook.com/groups/213622388659450/search/?query=ass\%C3\%A9dio\&epa=SEARCH_BOX

A resposta apresentada na figura 2 sinaliza um movimento de discordância por parte dos participantes do grupo em relação à defesa do estudante, o que se configura em Culpeper (2003) como estratégia de impolidez positiva, cujo objetivo é desacreditar a imagem compartilhada. No primeiro comentário, embora não apareçam ostensivamente indícios de impolidez, a autora realizou o ato de forma sutil em dois momentos, quando realizou a retomada do termo "rapaz" por "macho", 
tendo sido a segunda palavra, dentro do contexto apresentado, uma expressão carregada de conteúdo histórico e conservador, amplamente repudiada naquele ambiente, caracterizando-se, assim, o machismo como um tabu, em especial quando são as mulheres quem assumem o controle do turno de fala. Ao final do comentário, ela realiza duas estratégias de impolidez negativa, a saber: Coloque o endividamento do outro em questão, quando apresentou a suposta negligência da Universidade em relação a casos semelhantes já expostos publicamente; e Associe explicitamente o outro com um aspecto negativo - personalize, use os pronomes "eu” e "você", quando incluiu outras pessoas pelo pronome indefinido "alguns", a fim de associar pessoas do grupo como agentes de práticas de assédio em situações anteriores.

Figura 3 - Comentários "Tautologia"

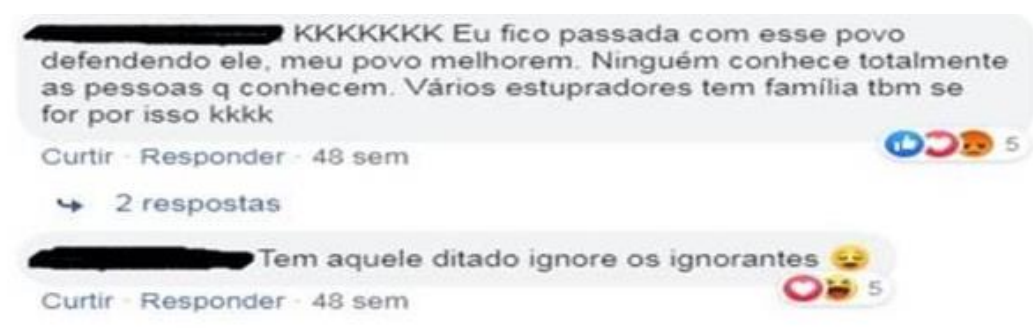

Fonte: https://www.facebook.com/groups/213622388659450/search/?query=ass\%C3\%A9dio\&epa=SEARCH_BOX

Na figura 3, observamos mais estratégias de impolidez. Desta vez, o uso repetido da letra "K" (o que indica risos) na abertura e no fechamento do turno de fala do terceiro comentarista sugere que se tratada estratégia de impolidez não trate o outro seriamente. Menospreze o outro. $\mathrm{O}$ uso da estratégia foi intensificado e pôde ser confirmado pela expressão "melhorem", indicando um relativo poder do enunciador em relação aos demais participantes do grupo. Vale ressaltar que, nesse mesmo comentário, a autora faz uso também de estratégias de polidez positiva alinhadas à postagem original. Ela contrapõe o argumento do denunciante, no momento em que enuncia: "ninguém conhece totalmente ninguém q conhece...". A tautologia funcionou como ferramenta de exposição de um conceito, como se fosse uma "verdade geral", impassível de discordância. Na mesma linha, seguiu o último comentário da figura, que, ao mesmo tempo que parece ser polido, é impolido, pois realiza a primeira estratégia de impolidez: ignore, censure o outro.

O comentário apresentado na figura 4 recorre a um processo literário e estilístico de retomada anafórica, uma espécie de paródia do que foi apresentado na figura 1. A autora do comentário da figura 4 fez uso dos mesmos recursos retóricos do denunciante, assim como das mesmas estratégias de polidez, mas usou o mecanismo da Inversão (VAN DIJK, 2017), levando a 
audiência da discussão a pensar sob o ponto de vista da suposta vítima de assédio. Nesse caso, o uso da Inversão reorienta a argumentação e passa a modificar o foco dos atos ameaçadores de face, que agora recaem sobre o denunciante. Esse movimento se explicita no uso da estratégia de impolidez linguística, cujos pronomes "eu" e "você" são, a todo tempo, realçados, negando ao denunciante qualquer alternativa de romper a associação com o que foi proferido.

Figura 4 - Comentário "Inversão"

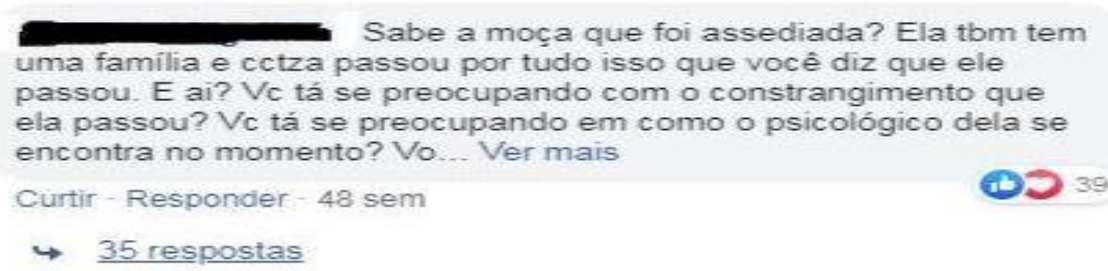

Fonte: https://www.facebook.com/groups/213622388659450/search/?query=ass\%C3\%A9dio\&epa=SEARCH_BOX

Antes de Freyre (1993), a mestiçagem era algo extremamente ruim, cogitava-se a devastação do país por uma mistura de negros, brancos e índios, e existia até um plano que tendia a embranquecer a população por meio do aumento da população branca. No entanto, ao aceitar a mestiçagem, na qual ilustrada na obra de Freyre (1993), o racismo passou a assumir novas facetas no Brasil. Em vez de uma estratificação racial, em que negros e índios viveriam separados dos brancos, os mestiços seriam uma nova categoria racial, em que a negação do passado com a África e com a negritude os colocaria como semideuses no cenário racial do Brasil pós-colonial.

Com base nisso, podemos dizer que os comentários demonstraram uma espécie de conflito entre o herói e o anti-herói expostos publicamente a partir da discussão do suposto caso de assédio. Desse modo temos duas personagens estigmatizadas historicamente: o negro e a mulher, o que, segundo Bacila (2015), constituem dois dos maiores estigmas da humanidade. Para o autor (2015), a mulher passou a ser vítima de preconceito quando assumiu as funções maternais, em vez de responsabilizar-se por atividades mais físicas. Os dois, negros e mulheres, nos últimos anos vêm trabalhando para conquistar seu lugar de fala (RIBEIRO, 2017) e se fazer representar, como parte de um processo de empoderamento.

Deste modo, discutir sobre situações como essas põe em xeque tópicos delicados, que requerem de seus enunciadores um alto investimento linguístico para que possam convencer a "platéia" (GOFFMAN,1966) de quem é "culpa". Isso é possível de ser feito por meio da (im)polidez linguística. 


\section{CONSIDERAÇÕES FINAIS}

Concebemos o preconceito como uma construção mental que se realiza nas instâncias cognitiva e social, e se manifesta através da materialização discursiva e física (quando, por exemplo, uma crença passa a ser um comportamento). Quando o preconceito alcança a esfera discursiva, manifestando-se na fala dos sujeitos, assistimos à intolerância na linguagem, que, por sua vez, realiza-se no uso de expressões ofensivas ou mesmo atenuadoras, que permitem a inferência do conteúdo preconceituoso ostensivo e velado.

Acreditamos que as estratégias de polidez e impolidez linguística circunscritas em contextos históricos, ideológicos e sociais são capazes de indicar crenças preconceituosas. Desse modo, este trabalho teve como objetivo compreender, a partir de Fanon (2008), VanDijk (2017) Brown e Levinson (1987) e Culpeper (1996; 2011), como o preconceito se materializa em (im)polidez linguística através de postagens no Facebook. Para isso, coletamos uma postagem e quatro comentários sobre um suposto caso de assédio sexual ocorrido nas intermediações da Universidade.

Os resultados sugeriram que os participantes do grupo alternavam entre as estratégias de polidez e impolidez para declararem o seu apoio ou o seu repúdio ao suposto agressor e àqueles que o apoiavam. Esse fato é importante, pois sinaliza a relação dicotômica entre o "eu" e o "outro". Nos comentários, encontramos mecanismos discursivos como a "inversão", funcionando como estratégia de atenuação do racismo e, ao mesmo tempo, focalizando outro tipo de preconceito (o de gênero). Assim, as estratégias de polidez e impolidez atuam em concomitância para gerar um maior efeito persuasivo. Este estudo não se propõe a adotar um posicionamento a respeito do caso, ao contrário, ele permite a reflexão sobre como os preconceitos transformam-se em intolerância, especialmente nos discursos de personagens estigmatizadas pela nossa história.

\section{REFERÊNCIAS}

ALLPORT, G. W. The nature of prejudice. New York: Basic books, 1979.

AUSTIN, J. L.. Quando dizer é fazer: palavras e ação. Porto Alegre: Artes Médicas, 1990.

BACILA, C. R.. Criminologia e estigmas: um estudo sobre os preconceitos. São Paulo: Atlas, 2015. BARROS, D.L.P.. A construção discursiva dos discursos intolerantes. In: BARROS, D.L.P.(Org.). Preconceito e intolerância: reflexões lingüístico discursivas. São Paulo: Universidade Presbiteriana Mackenzie, 2011.

BROWN, P.; LEVINSON, S. Politeness: some universals in languageusage. In: GOODY, E. (Ed.). Questions and Politeness. Cambridge: Cambridge University Press, 1978.

BROWN, P.; LEVINSON, S. Politeness: some universals in language usage. Cambridge: University Press, 1987. 
CULPEPER, J. Towards an anatomy of impoliteness. Journal of pragmatics, v. 25, n. 3, p. 349-367, 1996. Disponível em: https://www.sciencedirect.com/science/article/abs/pii/0378216695000143 Acesso em: 02 jul. 2019.

CULPEPER, J. Impoliteness: using language to cause offence. New York: Cambridge Press, 2011.

DAVIS, A. Y. Women, race, \& class. New York: Vintage, 1981. Disponível em:https://legalform.files.wordpress.com/2017/08/davis-women-race-class.pdf Acesso em: 05 maio 2019.

FANON, F. Pele negra, máscaras brancas. Salvador: EDUFBA, 2008. Disponível em: https://www.geledes.org.br/wpcontent/uploads/2013/08/Frantz_Fanon_Pele_negra_mascaras_brancas.pdf Acesso em: 05 maio 2019.

FREYRE, G. Casa grande e senzala: formação da família brasileira sob o regime de economia patriarcal. Rio de Janeiro: Editora Record, 1993.

GOFFMAN, E..Estigma: notas sobre a manipulação da identidade deteriorada. Nova Jersey: Prentice-Hall, 1963.

GOFFMAN, E. Behavior in public places: notes on the social organization of gatherings. New York: Free Press, 1966.

GOFFMAN, E. Interaction ritual: essays on face-to-face behavior. Garden City: Anchor Doubleday, 1967.

GUIMARÃES, A. S. A. Entre o medo de fraudes e o fantasma das raças. Horizontes Antropológicos, v. 11, n. 23, p. 215-217, 2005.

HIRATA, H.. Gênero, classe e raça Interseccionalidade e consubstancialidade das relações sociais. Tempo Social, v. 26, n. 1, p. 61-73, 2014.

KERBRAT-ORECCHIONI, C. Análise da conversação: princípios e métodos. São Paulo: Parábola, 2006.

LAKOFF, G.; JOHNSON, M. Metaphors we live by. University of Chicago Press, 1980.

LAKOFF, R. The logic of politeness; or, minding your P's and Q's. In: CORUM, C.; SMITHSTARK, T. C.; WEISER, A. (Eds.). Papers from the Ninth Regional Meeting of the Chicago Linguistics Society. Chicago: University of Chicago Press, p. 292-305, 1973.

LEITE, M.Q. Preconceito e intolerância na linguagem. São Paulo: Contexto, 2017.

LEECH, G. M. Principles of Pragmatics. London: Longman, 1983.

LEECH, G. N. The pragmatics of politeness. USA: Oxford University Press, 2014.

MARTINS, A. R. D.. A violência linguística virtual contra a mulher: ideologia e estratégias de (im)polidez em blogs. 2013. 161 f. Dissertação (Mestrado em Linguística Aplicada) - Programa de Pós-Graduação em Linguística Aplicada, Universidade Estadual do Ceará, Fortaleza, 2013. Disponível em: http://www.uece.br/posla/dmdocuments/Adriana\%20Regina\%20Dantas\%20Martins.pdf. Acesso em: 02 jul. 2019

MUNANGA, K.. Rediscutindo a mestiçagem no Brasil: identidade nacional versus identidade negra. Petrópolis: Editora Vozes, 1999.

PAIVA, G. M. F.; MOREIRA, R. G.; SANTOS, L. A. P. F. Introdução aos Estudos de (Im)Polidez Linguística. Fortaleza: Centro Universitário Estácio do Ceará, 2016. Disponível em: http://publica- 
estaciofic.com.br/edicoes/LIVROS/IMPOLIDEZ-FINAL/index.html Acesso em: 02 de julho de 2019.

RIBEIRO, D. O que é lugar de fala? Belo Horizonte: Letramento, 2017.

SEARLE, J. R. Speech acts: an essay in the philosophy of language. Cambridge: Cambridge University Press, 1969

SEARLE, J. R. What is an intentional state? Mind, v. 88, n. 349, p. 74-92, 1979. Disponível em: https://www.jstor.org/stable/2253065?seq=1 Acesso em: 01 jul. 2019.

VAN DIJK. Discurso e poder. São Paulo: Contexto, 2017.

WATTS, J. R. Politeness: key topics in sociolinguistics. Cambridge: Cambridge University Press, 2003. 